\title{
Altered cytokine expression in Helicobacter pylori infected patients with bleeding duodenal ulcer
}

\author{
Ljiljana Milic ${ }^{*}$, Aleksandar Karamarkovic ${ }^{1}$, Dusan Popadic ${ }^{2}$, Ana Sijacki ${ }^{3}$, Ilijana Grigorov ${ }^{4}$, Emina Milosevic ${ }^{2}$, \\ Vladica Cuk ${ }^{1}$ and Predrag Pesko ${ }^{5}$
}

\begin{abstract}
Objective: Peptic ulcer disease is a condition in which an important role has infection with H. pylori. The most common complication of peptic ulcer is bleeding. The presence of $H$. pylori triggers local and systemic cytokine signaling which may affect processes such as healing, gastric or duodenal rupture, and carcinogenesis. In this study, we examined the concentrations of IL-1 $\beta, I L-6, I L-10$, TNF, TGF- $\beta$ and IL-17A in serum by enzyme immunoassay and their mRNA expressions in periulcer biopsies obtained from patients with bleeding peptic ulcer by means of real-time-PCR.

Results: We have shown that pro-inflammatory IL-6 and TNF concentrations in serum were significantly higher in patients who were infected with H. pylori, while the concentrations of TGF- $\beta$ and IL-17A were significantly lower compared to non-infected subjects. IL-17A expression in periulcer mucosa was significantly higher in patients who were infected with H. pylori, while the expression of other cytokines, there was no significant difference compared to noninfected controls. Considering higher serum concentrations in non-infected subjects and higher IL-17A expression in mucosal tissue of infected patients, our data support the studies that found IL-17A has protective role in eradication of H. pylori infection in infected patients.
\end{abstract}

Keywords: Bleeding ulcer, Proinflammatory cytokines, Helicobacter pylori, Real-time-PCR

\section{Introduction}

Bleeding is one of the most common complications of duodenal ulcer. European data show that $10-50$ of every 100,000 hospitalizations are due to ulcer bleeding [1]. Mucosal damage and the duodenal ulcer formation usually occur as a result of interplay between acidopeptic effects of hydrochloric acid and pepsin, treatment with nonsteroidal anti-inflammatory drugs (NSAIDs), and the presence of $H$. pylori infection [2]. H. pylori infection of the gastric mucosa leads to sequence of events that trigger inflammatory response, with production of cytokines and the activation of neutrophils [3]. The peptidoglycan within its cell wall is recognized

\footnotetext{
*Correspondence: ljilja.milic@gmail.com

${ }^{1}$ Surgical Clinic "Nikola Spasić", Zvezdara University Medical Center,

Faculty of Medicine, University Belgrade, Dimitrija Tucovića 161,

11000 Belgrade, Serbia

Full list of author information is available at the end of the article
}

by the cytoplasm sensor Nod 1, which stimulates the expression of numerous cytokines that promote inflammation (IL-1 $\beta$, IL-6, IL-8, and TNF) but also cytokines that reduce the inflammatory response (IL-4, IL-10) $[4,5]$. Protein virulence factors of $H$. pylori increase TGF $\beta$, but the in acute infection decreased levels of this cytokine were found. This is in contrast to upregulated TGF $\beta$ levels in chronic infection [6]. Even though TGF- $\beta$ is immunosuppressive cytokine that induces $\mathrm{T}$ regulatory cells, it is also one of the polarizing cytokines for pro-inflammatory Th17 cells [7]. IL-17A, a major cytokine of Th17 population is upregulated in H. pylori infection [8]. The net result of the local proinflammatory and anti-inflammatory cytokines interplay remains elusive, although it may significantly influence processes such are lesion healing, rupture of the gastric wall and even carcinogenesis. The aim of this study was to investigate the influence of the infection with $H$. pylori on the local inflammatory response 
measured by the IL- $1 \beta$, IL-6, IL-10, TNF, TGF- $\beta$ and IL-17A mRNA expression in patients with bleeding duodenal ulcer, as well as to determine serum concentrations of IL- $1 \beta$, IL- 6 , IL-10, TNF, TGF- $\beta$ and IL-17A in those patients.

\section{Main text \\ Methods}

The study was conducted at the Department of Emergency Surgery of Emergency Center, Clinical Center of Serbia in Belgrade. Written informed consent was obtained from each subject, and the study protocol was approved by the Ethical Committee of University Clinical Center of Serbia. The study included consecutive patients taking NSAIDs aged 20 to 70 years with bleeding duodenal ulcers that fulfilled inclusion and exclusion criteria (successive patients' samples were collected until the number of 30 patients per group was reached). The study group consisted of 30 patients with $H$. pylori infection, while the control group had 30 patients without $H$. pylori infection, as determined by routine urease test and histology. Patients with diabetes, cancer, chronic inflammatory diseases (e.g. rheumatoid arthritis and psoriasis), or autoimmune diseases were excluded from the study. Demographic data are shown in a Table 1 . Blood counts for the $H$. pylori positive participants were: red blood cells (RBC) $3.34 \pm 1.26\left(10^{12} \mathrm{~L}^{-1}\right)$, hemoglobin $(\mathrm{Hb}) 9.43 \pm 2.37(\mathrm{~g} /$ $\mathrm{dL}$ ), hematocrit (Ht) $0.28 \pm 0.07$ ( $\mathrm{vol} / \mathrm{vol})$, and platelets (Plt) $209.10 \pm 51.52\left(10^{9} \mathrm{~L}^{-1}\right)$. Blood counts for the H. pylori negative participants were RBC $2.70 \pm 0.51$ $\left(10^{12} \mathrm{~L}^{-1}\right), \mathrm{Hb} 8.04 \pm 1.79(\mathrm{~g} / \mathrm{dL}), \mathrm{Ht} 0.22 \pm 0.05$ (vol/ vol), Plt $233.00 \pm 71.22\left(10^{9} \mathrm{~L}^{-1}\right)$. All patients were given esophagoduodenoscopy, and endoscopic finding was described by Forrest classification [9]. This classification is used to assess risk for rebleeding and mortality $[10,11]$. Forrest Ia (FIa) finding was not found. In the study group 5 patients (16.6\%) FIb was found, 8 patients (26.6\%) FIIa was found, 8 patients (26.6\%) FIIb was found, 9 patients (30\%) FIIc was found. In the control group 9 patients (30\%) FIb was found, 12 patients

Table 1 Demographic data

\begin{tabular}{lllll}
\hline Variable & HbP+ & HbP $\varnothing$ & Total & $\mathbf{p}$ \\
\hline Gender & & & & \\
Male & $26(86.7 \%)$ & $28(93.4 \%)$ & $54(90.0 \%)$ & NS \\
Female & $4(13.3 \%)$ & $2(6.6 \%)$ & $6(10.0 \%)$ & \\
Age (mean士SD) & $50.9 \pm 13.2$ & $53.3 \pm 11.8$ & $52.1 \pm 12.5$ & NS \\
\hline
\end{tabular}

(40\%) FIIa was found, 8 patients (26.6\%) FIIb was found, 1 patients (3.3\%) FIIc was found.

\section{$R N A$ isolation, reverse transcription and qPCR for determination of cytokine $m R N A$ expression in gastric mucosa}

All RNA related procedures were done by independent investigators blinded to the clinical data. Tissue samples obtained by biopsies were homogenized with Teflon micropestle (Eppendorf) in $2 \mathrm{~mL}$ tubes (Eppendorf) in $1 \mathrm{~mL}$ of TRIZOL ${ }^{\circledR}$ reagent (Invitrogen). Total RNA from all samples was extracted according to the manufacturer's instructions. Integrity of extracted RNA was verified by electrophoresis on 1.2\% agarose gel. Approximately $1 \mu \mathrm{g}$ of RNA, determined by optical density reading at $260 \mathrm{~nm}$, was used in the reverse transcriptase reaction using M-MuLV RT (Fermentas) with random hexamers (Fermentas) according to the manufacturer's instructions. Oligonucleotides for human IL-1 $\beta$, IL-6, IL-10, TNF, TGF- $\beta$, IL-17A and glyceraldehyde-3-phosphate dehydrogenase (GAPDH) sequences were designed using Primer Express (ABI) and purchased from Metabion. Primers were designed so that amplicons spanned intron/ exon boundaries to minimize amplification of genomic DNA. Sequences, final concentrations and labels of the oligonucleotides were as shown in Additional file 1: Table S1.

To ensure normalization for the amount of starting cDNA each tested gene was amplified simultaneously with GAPDH. All Real-time PCR experiments were performed in 96-well reaction plates (MicroAmp Optical, $\mathrm{ABI})$ in $20 \mu \mathrm{L}$ volume/well. PCR mixes for determination of IL-1 $\beta-\beta$, IL- 6 , IL-10, TNF, TGF- $\beta$ and GAPDH contained $12 \mu \mathrm{L}$ of master mix $(10 \mu \mathrm{L}$ of $2 \mathrm{X}$ Maxima SYBR Green qPCR Master, $1 \mu \mathrm{L}$ of $20 \times$ concentrated primers for the respective genes and $1 \mu \mathrm{L}$ of water) and $8 \mu \mathrm{L}$ of appropriate sample diluted 1 to 8 in demineralized water. For determination of IL-17 we used $12 \mu \mathrm{L}$ of master mix (10 $\mu \mathrm{L}$ of $2 \mathrm{X}$ Maxima mix-Probe, Fermentas, and $2 \mu \mathrm{L}$ of oligonucleotide mixture for the IL-17 and GAPDH containing primers and probes) and $8 \mu \mathrm{L}$ of appropriate sample diluted 1 to 8 in demineralized water. The plates were sealed with optical adhesive film (ABI), briefly centrifuged at high speed and thereafter placed into the thermocycler (Mastercycler ep Realplex ${ }^{2}$, Eppendorf). The thermal cycle conditions were $95^{\circ} \mathrm{C}$ for 4 min followed by 40 cycles that were run for $15 \mathrm{~s}$ at $95^{\circ} \mathrm{C}$ and for $1 \mathrm{~min}$ at $60^{\circ} \mathrm{C}$ with the melting curve analysis after the last step of amplification. Melting curve analysis step was omitted for the determination of IL-17 and GAPDH expression. For qPCR and melting curve performing and data acquisition Realplex software (Eppendorf) was used. 
The levels of expression of IL-1 $\beta$, IL-6, IL-10, TNF, TGF- $\beta$ and IL-17A were standardized against GAPDH gene levels as a reference gene. All assays were performed in duplicates. The expression levels of the target genes were expressed in arbitrary units as the ratio of target and reference gene $\left(1 / 2^{-\Delta C t}\right)$.

\section{Enzyme immunoassays for determination of blood cytokines concentrations}

At the enrollment, serum (or plasma for determination of TGF- $\beta$ ) was obtained from a sample of venous blood drawn before endoscopy, and frozen at $-20{ }^{\circ} \mathrm{C}$ for later determination of cytokines. The concentrations of IL-1 $\beta$, IL-6, IL-10, TNF, TGF- $\beta$ and IL-17A are measured by ELISA tests (eBioscience, ELISA Ready-SET-Go!) Each measurement was done according to the manufacturer's instructions. The cytokine detection limits in serum were: $1.95 \mathrm{pg} / \mathrm{mL}$ for IL-1 $\beta ; 3.91 \mathrm{pg} / \mathrm{mL}$ for IL-6; $0.59 \mathrm{pg} /$ $\mathrm{mL}$ for IL-10; $0.975 \mathrm{pg} / \mathrm{mL}$ for TNF; $31.25 \mathrm{pg} / \mathrm{mL}$ for TGF- $\beta$, and $7.81 \mathrm{pg} / \mathrm{mL}$ for IL-17A.

\section{Statistical analysis}

Scale data for mRNA and protein levels of the aforementioned cytokines was tested for normality by Kolmogorov-Smirnov test. Normally distributed data were compared by Student's t-test. Otherwise, Mann-Whitney $\mathrm{U}$ test was applied. Categorical data were compared by Pearson's Chi Square or Fisher's exact significance test, where necessary. The $\mathrm{p}<0.05$ was considered significant. For the statistical analysis SPSS software 11.5 (SPSS Inc., Chicago, IL) was used.

\section{Results}

\section{Cytokine mRNA expression in periulcer mucosa}

We analyzed IL-1 $\beta$, IL-6, IL-10, TNF, TGF- $\beta$ and IL-17A gene expression in periulcer mucosa of $H$. pylori positive and $H$. pylori negative patients by means of qPCR to determine local cytokine response to $H$. pylori infection. The results demonstrated that the expression of IL-17A mRNA of $H$. pylori positive patients was higher in comparison with that of $H$. pylori negative patients $(\mathrm{p}<0.01)$ (Fig. 1). Unexpectedly, the expression of proinflammatory mediator TNF mRNA was not significantly increased in mucosa of $H$. pylori positive patients when compared to the values obtained in samples from $H$. pylori negative patients (Fig. 1). There was also no significant difference in expression of anti-inflammatory TGF- $\beta$ and IL-10 mRNAs between $H$. pylori positive patients and $H$. pylori negative patients (Fig. 1).

\section{Blood cytokine concentrations}

To determine systemic response to $H$. pylori infection we measured concentrations IL-1 $\beta$, IL-6, IL-10, TNF, TGF- $\beta$ and IL-17A in blood samples of all patients (Fig. 2). The concentrations of TGF- $\beta$ and IL-17A were significantly higher in non-infected patients (Fig. 2) than in patients with $H$. pylori infection. Concentrations of IL-1 $\beta$, IL-6, IL-10, and TNF inclined toward higher values in patients with $H$. pylori infection compared to those without infection but the difference did not reach the level of statistical significance. Cytokine detectability was: TGF- $\beta-100 \%$, IL-1 $\beta-35.0 \%$, IL-6-85.0\%, IL-10-56.7\%, TNF-28.3\%, and for IL-17-50.0\%. Proportion of cytokine detectable samples did not differ statistically significantly between H. pylori positive and negative patients, except for IL-17, where the proportion of positive samples was significantly higher in the $H$. pylori negative patients.

\section{Discussion}

The analysis of IL-1 $\beta$ mRNA expression in biopsy material, demonstrated that most patients had detectable values of IL- $1 \beta$ mRNA. The difference in IL-1 $\beta$ mRNA between these two groups was not significantly significant but the median of IL-1 $\beta$ mRNA expression was higher in patients with $H$. pylori infection. Similar data was published by several groups, and it is generally accepted that $H$. pylori infection increases of IL- $1 \beta$ mRNA expression as a local immune response $[3,12,13]$. Expectedly, median values of serum IL- $1 \beta$ were higher in the group with $H$. pylori infection, but without statistical significance.

Measurements of circulating IL- $1 \beta$ revealed that only a third of patients had value within the limits of sensitivity of the test. Since all the patients were using NSAIDs, one can speculate that these drugs hindered several cytokines' production to undetectable levels in a portion of patients. NSAIDs used by our patients were diclofenac and ibuprofen. Ibuprofen did not affect plasma cytokine levels (namely IL-1 $\beta$, TNF, IL-6, and IL-10) of healthy people [14]. However, there is conflicting data on effect of ibuprofen on cytokine levels in specific tissues $[15,16]$. Diclofenac reduced plasma TNF in a study on mildly obese volunteers [17] so it could be that it affected detectability of this cytokine in our hands, too. Yet in the same study, diclofenac did not altered IL-10 levels, and IL- $1 \beta$ and IL- 6 were omitted from the analysis due to high rate of undetected levels, even though the more sensitive platform (bead-based multiplex sandwich immunofluorescence assay vs. ELISA) was used. To the best of our knowledge, there is no data how ibuprofen and diclofenac affect serum IL-17A levels.

Literature search did not reveal any article investigating IL- $1 \beta$ in sera of patients with bleeding duodenal ulcer in relation to $H$. pylori infection.

Local IL-6 mRNA expression was significantly higher in H. pylori infected patients compared to non-infected, 

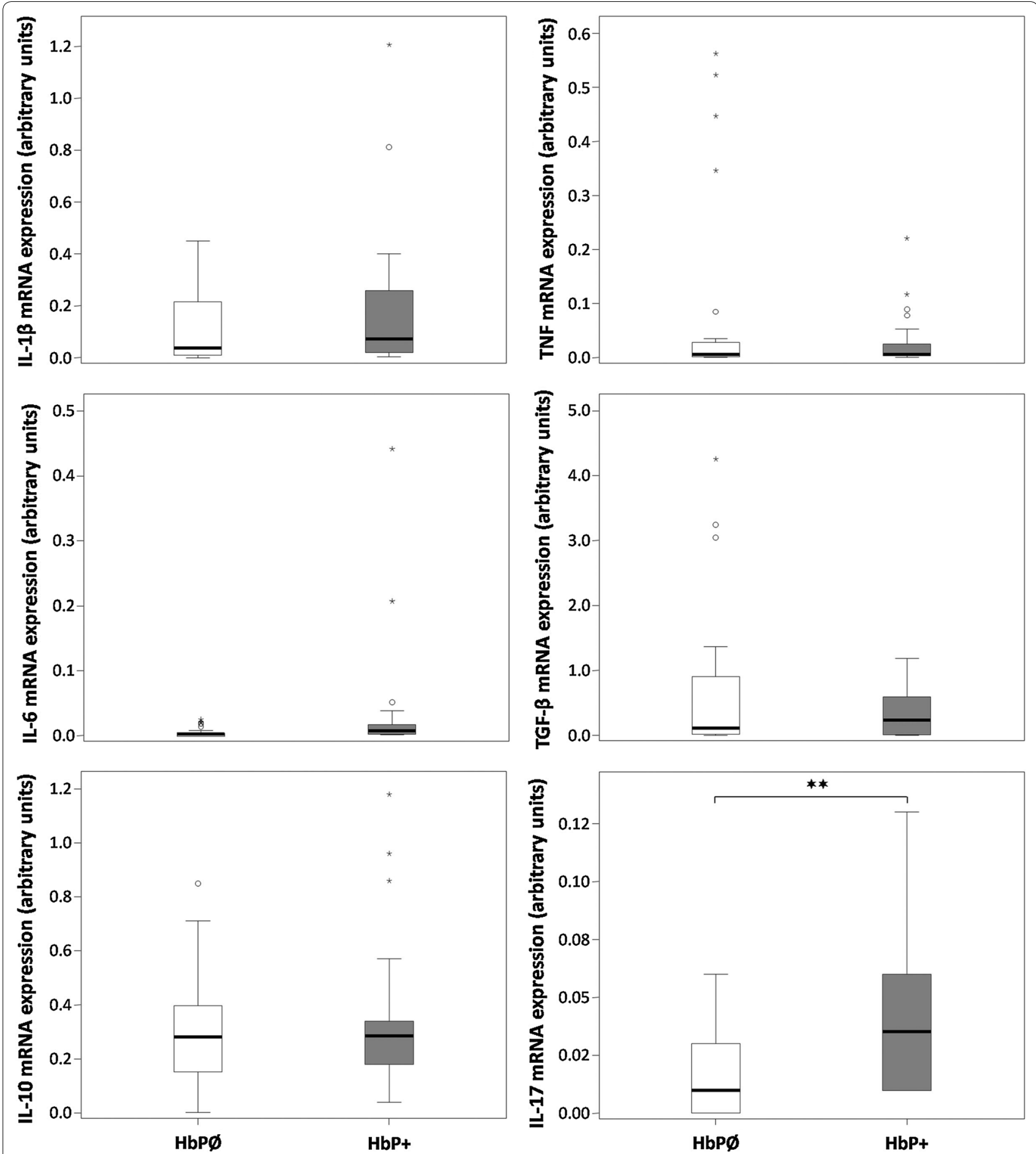

Fig. 1 Expression of IL-1 $\beta$, IL-6, IL-10, TNF, TGF- $\beta$ i IL-17A mRNAs in gastric mucosa of H. pylori-positive patients (HbP+) and the ones without H. pylori infection ( $\mathrm{HbP \varnothing}$ ) were quantified by real-time PCR. The relative expression of each target gene is presented in arbitrary units after normalization with GAPDH mRNA expression (see Materials and methods). Data are presented in the box-plot format in which cross line represents median, rectangle represents interquartile range, whiskers represents maximal and minimal values in 1.5 interquartile range, whereas outlier and extreme values are represented by circles and stars respectively, $* * p<0.01$ 


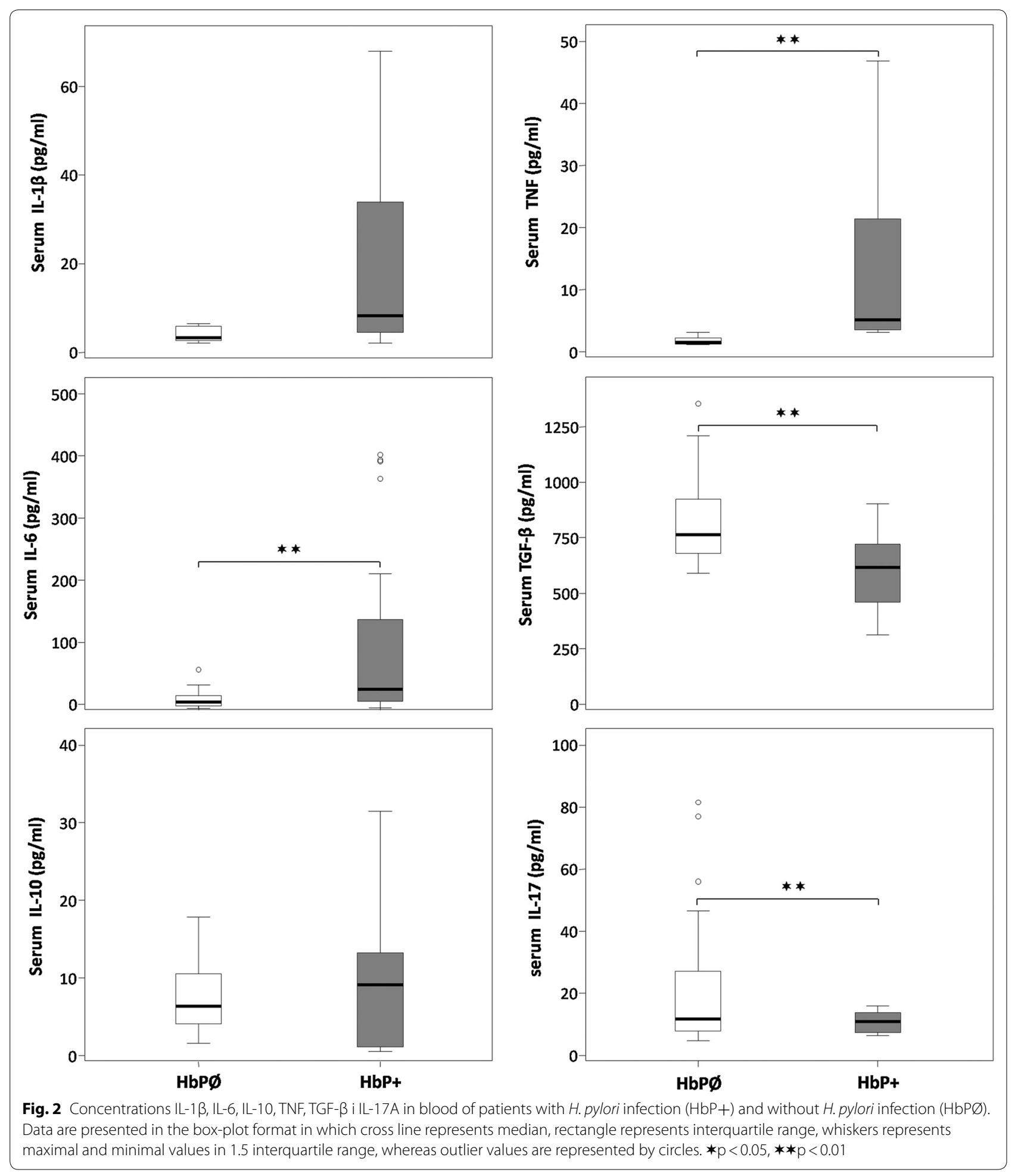

resembling to the results reported by Ströberg et al. [3]. Another study, carried out by Ren et al. has shown elevated IL-6 in antral biopsy of patients with chronic gastritis when infected with $H$. pylori, measured by enzyme immunoassay [18]. Expectedly, serum IL-6 values were significantly higher in patients with $H$. pylori infection compared to non-infected. The results of the IL-6 serum concentrations in our study are in line with those from 
Cichoz-Lach et al. who demonstrated that $H$. pylori infected, but not non-infected patients with erosive gastritis have higher values of IL- 6 compared to matched healthy controls [19].

The difference in TNF mRNA expression between the two groups of patients in duodenal biopsy material did not reach the level of statistical significance. Bontems et al. also found very similar values of TNF between patients with dyspepsia infected and uninfected with $H$. pylori [20]. Our finding partially disagrees with the previously reported data from Goll et al. demonstrating generally higher TNF mRNA expression in mucosa following H. pylori infection [4]. However, TNF mRNA expression in aforementioned study was lowest in patients with duodenal ulcers compared to other $H$. pylori infected patients, approaching values determined in non-infected patients and without statistical significance. TNF in serum was increased in infected patients, presumably as a response to the infection. However, further studies addressing serum TNF in $H$. pylori infected patients are warranted, since equivocal results were published previously, probably due to different clinical settings [21-23].

Our study demonstrates that half of patients without H. pylori infection had a detectable IL-17A mRNA in the biopsy tissue, while this cytokine mRNA was measurable in all the infected patients. Patients infected with H. pylori had significantly higher IL-17A mRNA expression in periulcer mucosa than non-infected patients. These results were expected due to the pro-inflammatory effect of infection with $H$. pylori and the type of the inflammatory response driven by IL-17A producing $\mathrm{T}$ cells e.g. recruitment of neutrophils. Our results are in the concordance with previously reported data [24]. Unexpectedly, serum concentrations of IL-17A were higher in patients without $H$. pylori infection. There is no published data to compare such a finding. Interestingly, higher serum concentration of IL-17 in uninfected patients might be protective in combating $H$. pylori [25, 26]. Jafarzadeh and coworkers reported higher serum levels of IL-17A in duodenal ulcer patients compared to healthy subjects and asymptomatic $H$. pylori infected individuals [27], but our result is based on the different study setup and therefore warrants replication.

IL-10 mRNA expression levels did not differ significantly in the two groups of our patients. In a study from Bontems et al. performed in 45 adults and children in Belgium, IL-10 mRNA expression was higher in infected children compared to non-infected, while in adults there was no differences between groups regarding $H$. pylori status [20]. In the study from Norway by Goll et al. [4] that included 91 subjects, IL-10 mRNA expression was elevated in mucosa of $H$. pylori positive patients compared to non-infected ones. This inconclusiveness could be partially explained by the heterogeneity of the patients groups. Patients recruited in our study had acute ulcer bleeding and took NSAIDs that may considerably affect local IL-10 mRNA expression by interfering with eicosanoids synthesis. Serum concentrations of IL-10 in serum, were similar in both groups of our patients resembling to the study of Russo and coworkers [22].

Although there was no statistically significant difference in TGF- $\beta$ mRNA expression between compared groups of patients, the median value of TGF- $\beta$ was higher in patients with $H$. pylori infection, consistently with the previously reported data $[3,28,29]$. TGF- $\beta$ in plasma was decreased in $H$. pylori infected patients compared to non-infected in line with results reported by $\mathrm{Ki}$ et al. demonstrating inverse relation between TGF- $\beta$ and anti H. pylori antibodies in blood [30].

We found higher serum concentrations in non-infected subjects and higher IL-17A expression in mucosal tissue of infected patients. Our data indicate that IL-17A might have protective role in $H$. pylori infection eradication in patients with bleeding ulcers. However, further studies assessing in-depth cellular and molecular mechanism of defense in $H$. pylori infection in larger cohorts of patients are necessary to address weather IL-17A has this protective role.

\section{Limitations}

A small number of patients were examined in the study, so a study involving a larger number of participants was required to confirm the results. Small sample size might be the reason of higher proportion of men with bleeding ulcer in this study compared to other studies in Serbian population [31].

\section{Additional file}

Additional file 1: Table S1. Sequences, final concentrations and labels of the oligonucleotides.

\section{Abbreviations \\ HbP: Helicobacter pylori; TNF: tumor necrosis factor; IL: interleukin; TGF-beta: transforming growth factor-beta; Real-time-PCR: real-time polymerase chain} reaction.

\section{Acknowledgements}

Not applicable.

\section{Authors' contributions}

LJM performed the research along with $\mathrm{AK}$, IG and VC, and drafted the manuscript. AK critically revised the manuscript and participated in the study design. AS critically revised the manuscript. DP performed $\mathrm{QPCR}$ and ELISA, analzyed the data, critically revised the manuscript and participated in the study design. EM performed the statistical analysis, and participated in preparing the manuscript. PP participated in the study design and performed 
critical revision of the manuscript. All authors read and approved the final manuscript.

\section{Funding}

This work has been supported by grant from the Ministry of Education, Science and Technological Development—Serbia (Grant No. 175038) and by Clinic for Emergency surgery, Emergency Center, University Clinical Center of Serbia.

\section{Availability of data and materials}

The datasets generated and/or analyzed during the current study are not publicly available due to the patients' privacy policy but are available from the corresponding author on reasonable request.

\section{Ethics approval and consent to participate}

All patients signed consent forms for data utilisation in the study as per Ethics Committee indication. Written informed consent was obtained from each subject, and the study protocol was approved by the Ethical Committee of University Clinical Center of Serbia.

\section{Consent for publication}

Not applicable.

\section{Competing interests}

The authors declare that they have no competing interests.

\section{Author details}

1 Surgical Clinic "Nikola Spasié", Zvezdara University Medical Center, Faculty of Medicine, University Belgrade, Dimitrija Tucovića 161, 11000 Belgrade, Serbia. ${ }^{2}$ Institute of Microbiology and Immunology, Faculty of Medicine, University Belgrade, Dr Subotica 1, 11000 Belgrade, Serbia. ${ }^{3}$ Clinic for Emergency Surgery, Emergency Center, University Clinical Center of Serbia, Faculty of Medicine, University Belgrade, Visegradska 26, 11000 Belgrade, Serbia. ${ }^{4}$ Department of Molecular Biology, Institute for Biological Research, Despota Stefana 142, 11000 Belgrade, Serbia. ${ }^{5}$ Clinic for Digestive Surgery, University Clinical Center of Belgrade, Faculty of Medicine, University Belgrade, Koste Todorovica No6, 11000 Belgrade, Serbia.

\section{Received: 10 March 2019 Accepted: 8 May 2019}

Published online: 15 May 2019

\section{References}

1. Fallah MA, Prakash C, Edmundowicz S. Acute gastrointestinal bleeding. Med Clin N Am. 2000;84(5):1183-208.

2. Halter F, Tarnawski AS, Schmassmann A, Peskar BM. Cyclooxygenase 2-implications on maintenance of gastric mucosal integrity and ulcer healing: controversial issues and perspectives. Gut. 2001;49(3):443-53.

3. Stromberg E, Edebo A, Svennerholm AM, Lindholm C. Decreased epithelial cytokine responses in the duodenal mucosa of Helicobacter pylori-infected duodenal ulcer patients. Clin Diagn Lab Immunol. 2003;10(1):116-24.

4. Goll R, Gruber F, Olsen T, Cui G, Raschpichler G, Buset M, et al. Helicobacter pylori stimulates a mixed adaptive immune response with a strong T-regulatory component in human gastric mucosa. Helicobacter. 2007;12(3):185-92.

5. Viala J, Chaput C, Boneca IG, Cardona A, Girardin SE, Moran AP, et al. Nod1 responds to peptidoglycan delivered by the Helicobacter pylori cag pathogenicity island. Nat Immunol. 2004;5(11):1166-74.

6. Li N, Xie C, Lu NH. Transforming growth factor- $\beta$ : an important mediator in Helicobacter pylori-associated pathogenesis. Front Cell Infect Microbiol. 2015;5:77.

7. Romagnani S. Regulation of the T cell response. Clin Exp Allergy. 2006;36(11):1357-66.

8. Bagheri N, Azadegan-Dehkordi F, Shirzad H, Rafieian-Kopaei M, Rahimian G, Razavi A. The biological functions of IL-17 in different clinical expressions of Helicobacter pylori-infection. Microb Pathog. 2015;81:33-8.

9. Forrest JA, Finlayson ND, Shearman DJ. Endoscopy in gastrointestinal bleeding. Lancet. 1974;2(7877):394-7.
10. Laine L, Peterson WL. Bleeding peptic ulcer. N Engl J Med. 1994;331(11):717-27.

11. Laine $L$, Jensen DM. Management of patients with ulcer bleeding. Am J Gastroenterol. 2012;107(3):345-60 (quiz 61).

12. Romero-Adrian TB, Leal-Montiel J, Monsalve-Castillo F, MengualMoreno E, McGregor EG, Perini L, et al. Helicobacter pylori: bacterial factors and the role of cytokines in the immune response. Curr Microbiol. 2010;60(2):143-55.

13. Wang M, Furuta $T$, Takashima M, Futami $H$, Shirai $N$, Hanai $H$, et al. Relation between interleukin-1 beta messenger RNA in gastric fundic mucosa and gastric juice $\mathrm{pH}$ in patients infected with Helicobacter pylori. J Gastroenterol. 1999;34(Suppl 11):10-7.

14. Lundeberg J, Feiner JR, Schober A, Sall JW, Eilers H, Bickler PE. Increased cytokines at high altitude: lack of effect of ibuprofen on acute mountain sickness, physiological variables, or cytokine levels. High Alt Med Biol. 2018;19(3):249-58.

15. Albuquerque AFM, Fonteles CSR, do Val DR, Chaves HV, Bezerra MM, Pereira KMA, et al. Effect of pre-emptive analgesia on clinical parameters and tissue levels of TNF-alpha and IL-1 beta in third molar surgery: a triple-blind, randomized, placebo-controlled study. Int J Oral Maxillofac Surg. 2017;46(12):1615-25.

16. Shahriari S, Rezaei A, Jalalzadeh SM, Mani K, Zamani A. Effect of ibuprofen on IL-1 beta, TNF-alpha and PGE2 levels in periapical exudates: a double blinded clinical trial. Iran J Immunol. 2011;8(3):176-82.

17. van Erk MJ, Wopereis S, Rubingh C, van Vliet T, Verheij E, Cnubben NH, et al. Insight in modulation of inflammation in response to diclofenac intervention: a human intervention study. BMC Med Genomics. 2010;3:5.

18. Ren Z, Pang G, Batey R, Routley D, Russell A, Musicka M, et al. Nonurease producing Helicobacter pylori in chronic gastritis. Aust N Z J Med. 2000;30(5):578-84.

19. Cichoz-Lach H, Slomka M, Celinski K, Baczek A. Level of serum cytokines in biliary gastritis and erosive gastritis with Helicobacter pylori coinfection. Ann Univ Mariae Curie Sklodowska Med. 2001;56:271-4.

20. Bontems P, Robert F, Van Gossum A, Cadranel S, Mascart F. Helicobacter pylori modulation of gastric and duodenal mucosal T cell cytokine secretions in children compared with adults. Helicobacter. 2003;8(3):216-26.

21. Bayraktaroglu T, Aras AS, Aydemir S, Davutoglu C, Ustundag Y, Atmaca $\mathrm{H}$, et al. Serum levels of tumor necrosis factor-alpha, interleukin-6 and interleukin-8 are not increased in dyspeptic patients with Helicobacter pylori-associated gastritis. Mediat Inflamm. 2004;13(1):25-8.

22. Russo F, Jirillo E, Clemente C, Messa C, Chiloiro M, Riezzo G, et al. Circulating cytokines and gastrin levels in asymptomatic subjects infected by Helicobacter pylori (H. pylori). Immunopharmacol Immunotoxicol. 2001:23(1):13-24.

23. Perri F, Clemente R, Festa V, De Ambrosio CC, Quitadamo M, Fusillo M, et al. Serum tumour necrosis factor-alpha is increased in patients with Helicobacter pylori infection and CagA antibodies. Ital J Gastroenterol Hepatol. 1999;31(4):290-4.

24. Kimang'a A, Revathi G, Kariuki S, Sayed S, Devani S, Vivienne M, et al. IL-17A and IL-17F gene expression is strongly induced in the mucosa of H. pylori-infected subjects from Kenya and Germany. Scand I Immunol. 2010;72(6):522-8.

25. Horvath DJ Jr, Washington MK, Cope VA, Algood HM. IL-23 contributes to control of chronic Helicobacter pylori infection and the development of T helper responses in a mouse model. Front Immunol. 2012;3:56.

26. Caruso R, Fina D, Paoluzi OA, Del Vecchio Blanco G, Stolfi C, Rizzo A, et al. IL-23-mediated regulation of IL-17 production in Helicobacter pylori-infected gastric mucosa. Eur J Immunol. 2008;38(2):470-8.

27. Jafarzadeh A, Mirzaee V, Ahmad-Beygi H, Nemati M, Rezayati MT. Association of the CagA status of Helicobacter pylori and serum levels of interleukin (IL)-17 and IL-23 in duodenal ulcer patients. J Dig Dis. 2009;10(2):107-12.

28. Beswick EJ, Pinchuk IV, Earley RB, Schmitt DA, Reyes VE. Role of gastric epithelial cell-derived transforming growth factor beta in reduced CD4+ T cell proliferation and development of regulatory T cells during Helicobacter pylori infection. Infect Immun. 2011;79(7):2737-45.

29. Li Z, Li J. Local expressions of TGF-beta1, TGF-beta1RI, CTGF, and Smad-7 in Helicobacter pylori-associated gastritis. Scand J Gastroenterol. 2006;41(9):1007-12. 
30. Ki MR, Shin DG, Park JS, Hong KS, Hong IH, Park JK, et al. Frequency of vacuolating cytotoxin A (VacA)-positive Helicobacter pylori seropositivity and TGF-beta1 decrease in atrial fibrillation. Int J Cardiol. 2010;145(2):345-6.

31. Sokic-Milutinovic A, Krstic M, Popovic D, Mijalkovic N, Djuranovic S, Culafic D. Role of Helicobacter pylori infection and use of NSAIDs in the etiopathogenesis of upper gastrointestinal bleeding. Acta Chir lugosl. 2007;54(1):51-62.

\section{Publisher's Note}

Springer Nature remains neutral with regard to jurisdictional claims in published maps and institutional affiliations.
Ready to submit your research? Choose BMC and benefit from:

- fast, convenient online submission

- thorough peer review by experienced researchers in your field

- rapid publication on acceptance

- support for research data, including large and complex data types

- gold Open Access which fosters wider collaboration and increased citations

- maximum visibility for your research: over $100 \mathrm{M}$ website views per year

At BMC, research is always in progress.

Learn more biomedcentral.com/submissions 